\title{
Tuberculosis Relapse in the Epididymis After the Completion of Nine Months of Anti-Tuberculosis Chemotherapy in a Patient with Poorly Controlled Diabetes Mellitus
}

\author{
Chikako Ichikawa,' \\ Sho Tanaka, iD ${ }^{2,3}$ \\ Masahiro Takubo, (D) 1,3 \\ Masaru Kushimoto, ${ }^{3}$ jin lkeda, ${ }^{3}$ \\ Katsuhiko Ogawa, ${ }^{3,4}$ \\ Ichiro Tsujino,, 3 Yutaka Suzuki, ${ }^{3,4}$ \\ Masanori Abe, (D) ${ }^{2}$ \\ Hisamitsu Ishihara, (D) \\ Midori Fujishiro ${ }^{1,3}$ \\ 'Division of Diabetes and Metabolic Diseases, \\ Department of Internal Medicine, Nihon \\ University School of Medicine, Tokyo, Japan; \\ ${ }^{2}$ Division of Nephrology, Hypertension and \\ Endocrinology, Department of Internal \\ Medicine, Nihon University School of Medicine, \\ Tokyo, Japan; ${ }^{3}$ Department of Internal \\ Medicine, Nihon University Hospital, Tokyo, \\ Japan; ${ }^{4}$ Division of Neurology, Department of \\ Medicine, Nihon University School of Medicine, \\ Tokyo, Japan; ${ }^{5}$ Division of Respiratory \\ Medicine, Department of Internal Medicine, \\ Nihon University School of Medicine, Tokyo, \\ Japan
}

Correspondence: Sho Tanaka Division of Nephrology, Hypertension and Endocrinology, Department of Internal Medicine, Nihon University School of Medicine, 30-I Oyaguchi Kamicho, Itabashi-ku, Tokyo, I73-86I0, Japan Tel +8I-3-3972-8I II

Fax +8|-3-3972-83 I I

Email tanakashol3@gmail.com

Midori Fujishiro

Division of Diabetes and Metabolic

Diseases Department of Internal

Medicine, Nihon University School of

Medicine, 30-I Oyaguchi Kami-cho,

Itabashi-ku, Tokyo, I73-8610, Japan

Tel +8I-3-3972-8I I I

Fax +8I-3-3972-8I99

Email fujishiro.midori@nihon-u.ac.jp

\begin{abstract}
The standard six-month tuberculosis (TB) treatment comprises an intensive phase lasting two months, followed by a continuation phase lasting four months. Meanwhile, the nine-month regimen, which has a prolonged continuation phase, is indicated for patients with complicated diabetes mellitus (DM) because of their poor response to treatment. A 61-yearold Japanese man with poorly controlled DM for five years presented with bilateral scrotal swelling noticed two weeks ago. He had a history of pleuritis, pericarditis, and peritonitis two years ago. These symptoms led to the diagnosis of culture-negative extrapulmonary TB. He received the nine-month chemotherapy regimen (isoniazid, rifampin, pyrazinamide, and ethambutol for two months, followed by isoniazid and rifampin for seven months), and his symptoms significantly improved. The swollen scrotum was accompanied by mild tenderness and pus discharge from a fistula. Imaging study revealed bilaterally diffusely enlarged epididymis. However, the acid-fast bacilli smear and culture and polymerase chain reaction using urine and pus discharge tested negative. Bilateral epididymectomy was performed. Although the acid-fast bacilli smear was negative, the pathology demonstrated granuloma formation and acid-fast bacilli tissue culture confirmed multi-drug resistant Mycobacterium tuberculosis. The optimal treatment regimen and duration for extrapulmonary TB with unknown drug susceptibility are debatable. The nine-month regimen can be insufficient in some cases. Thus, detailed follow-up is essential, and TB relapse should be thoroughly monitored.
\end{abstract}

Keywords: chemotherapy, diabetes mellitus, tuberculosis, epididymitis

\section{Introduction}

Tuberculosis (TB) is an infectious disease caused by pathogenic acid-fast bacilli (AFB), Mycobacterium tuberculosis (Mtb). Although TB incidence has gradually decreased, TB has remained ubiquitous as the leading cause of infectious diseaserelated death in adults. ${ }^{1}$ Inhaled droplet aerosols containing Mtb can develop a primary infection in the lungs. This results in a rapidly progressive active disease or a latent TB infection that may lead to active disease. The risk of progression to active disease after $M t b$ exposure is dependent on multiple factors. Diabetes mellitus (DM) has been associated with an increased risk of active TB. ${ }^{2,3}$

The objectives of TB therapy include eradicating $M t b$ to achieve a long-term cure and prevent drug resistance development during chemotherapy. For newly diagnosed 
TB patients, the six-month regimen is preferred due to its effectiveness. ${ }^{4}$ This comprises eight weeks of intensive phase quadruple therapy with the first-line anti-TB drugs (isoniazid (INH), rifampin (RIF), pyrazinamide (PZA), and ethambutol (EMB)), followed by 18 weeks of the continuation phase with INH and RIF. ${ }^{4}$ Meanwhile, the success of chemotherapy depends on multiple factors and host characteristics. The co-existence of DM is associated with a poor treatment outcome. Thus, the nine-month regimen (standard six-month regimen plus extended continuation phase therapy for three months) is considered for TB patients with DM. ${ }^{4,5}$ However, the optimal treatment regimen and duration for patients with $M t b$ isolation failure have not been established.

We describe a DM patient who experienced TB relapse in the epididymis after completing nine months of TB chemotherapy for pleural, pericardial, and peritoneal involvements.

\section{Case Description}

A 61-year-old Japanese man presented with bilateral scrotal swelling noted two weeks ago. The patient had a five-year history of hypertension and DM. His current medications included amlodipine (10 mg/day), azilsartan (20 mg/day), bisoprolol (5 mg/day), linagliptin ( $5 \mathrm{mg} /$ day), and empagliflozin (10 mg/day). His DM has been poorly controlled, and his glycated hemoglobin (HbA1c) level remained within $7-8 \%$ during the treatment period. He had no family history of TB. He was a social drinker and a non-smoker.
Two years before presenting to our service, the patient was admitted to the hospital for investigation and treatment of newly developed dyspnea and fatigability. During that hospital stay, pleuritis, pericarditis, and peritonitis were identified (Figure 1A and B). However, despite extensive investigations, including repeated AFB smear, AFB culture, and $M t b$ polymerase chain reaction (PCR) using sputum, blood, urine, and pleural, pericardial, and peritoneal effusions, failed to determine the etiology. However, TB was strongly suspected due to a positive interferon-gamma release assay; lymphocytepredominant pleural, pericardial, and peritoneal effusions with high adenosine deaminase levels; pleural membrane pathology, which demonstrated epithelioid cell granuloma with Langhans giant cells and caseous necrosis. Although $M t b$ was not isolated, TB chemotherapy was administered due to the high likelihood of having TB and his serious illness.

The patient underwent two months of intensive phase treatment comprising INH, RIF, PZA, and EMB with supervision. This was followed by seven months of the continuation phase with INH and RIF. After the treatment regimen, marked clinical and radiographic improvements were observed (Figure 1C and D). Four months after completing chemotherapy, while the patient was asymptomatic, a lowintensity area in the prostate was incidentally found on follow-up computed tomography. Magnetic resonance imaging confirmed a prostate mass (Figure 2). Biopsy of the prostate did not confirm a malignancy, but it revealed epithelioid cell granuloma with Langhans giant cells and caseous necrosis.
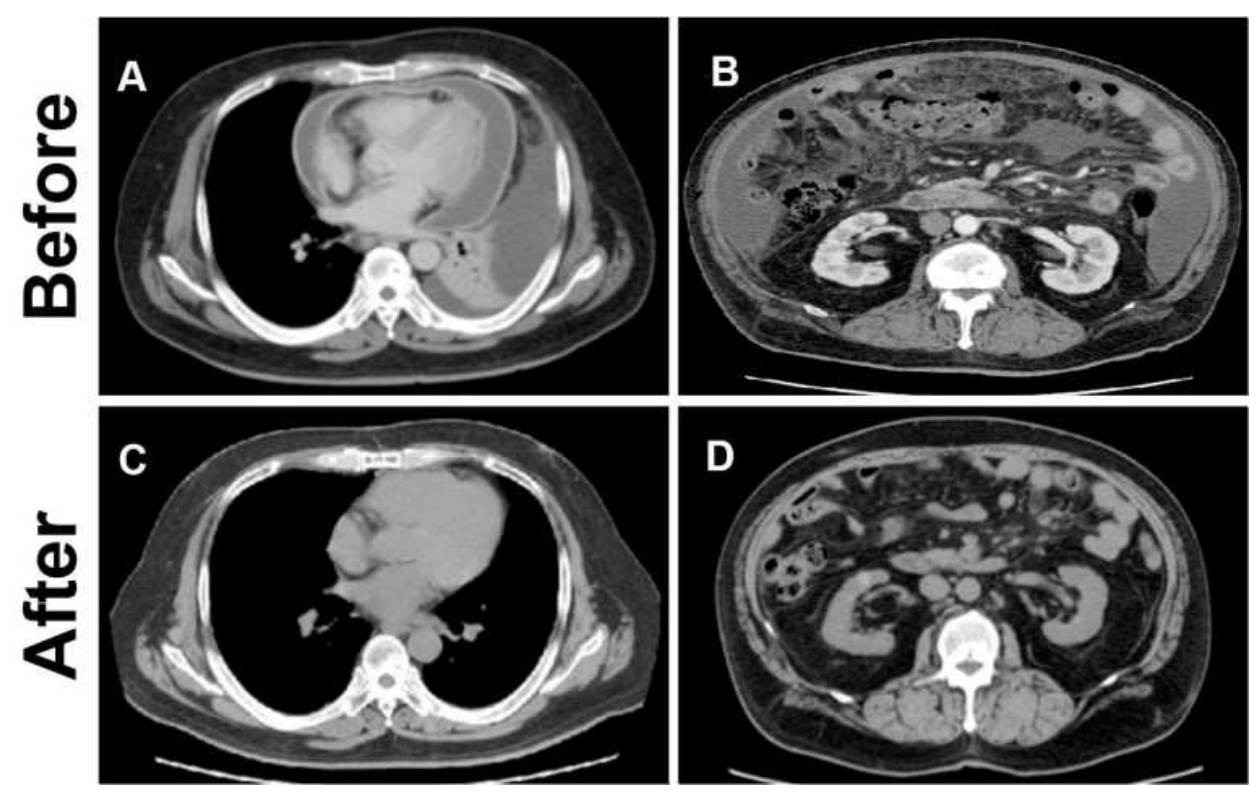

Figure I Imaging findings of pleural, pericardial, and peritoneal involvements. (A and B) Contrast-enhanced images of the chest and abdomen before chemotherapy. (C and D) Images without enhancement of the chest and abdomen after chemotherapy. Thickened pericardium, pericardial effusion, pleural effusion, and ascites found before treatment disappeared after chemotherapy. 

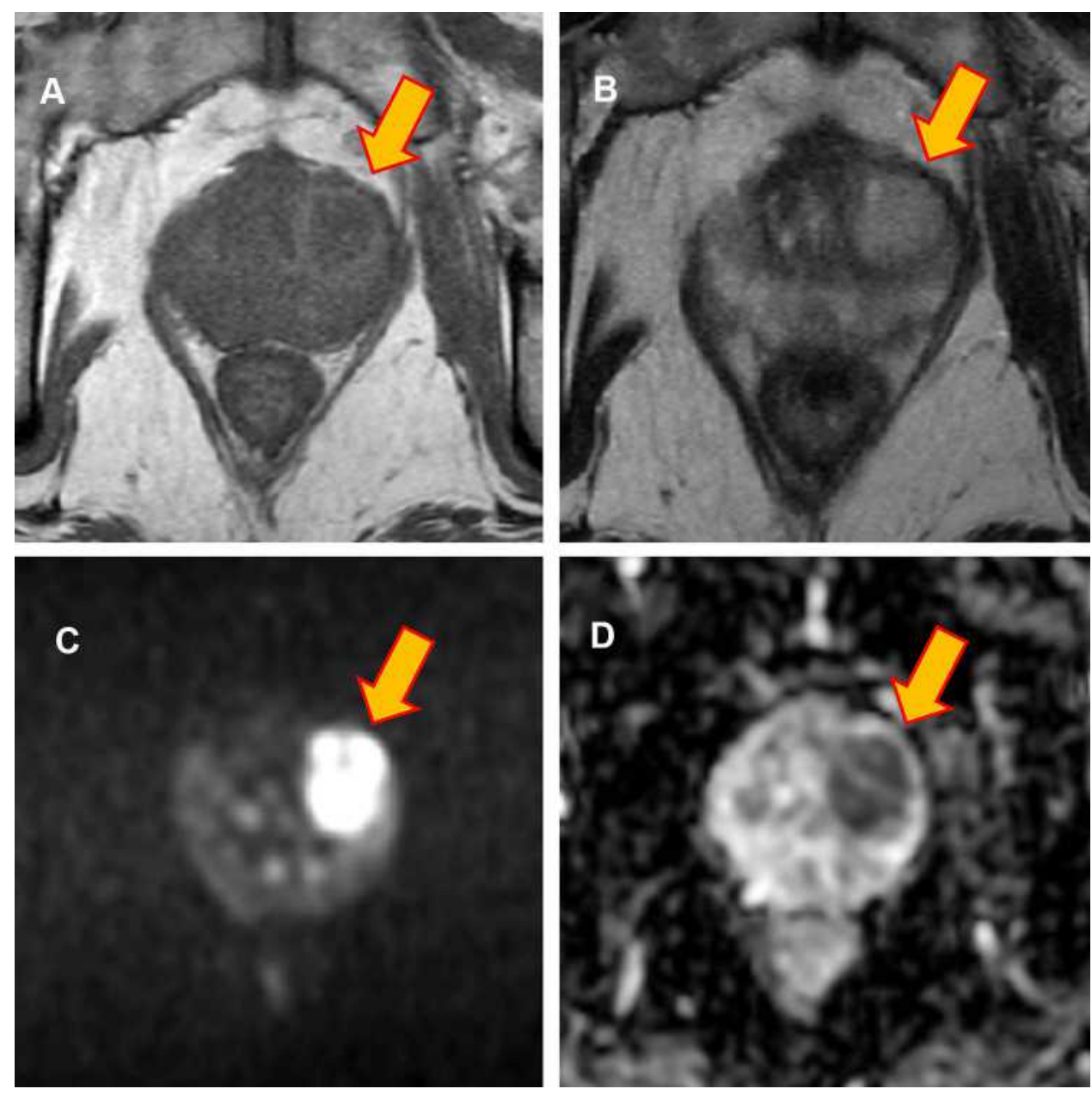

Figure 2 Magnetic resonance imaging of the prostate. Horizontal planes on magnetic resonance imaging are shown. The yellow arrow indicates the tumor. (A) TI-weighted image; the tumor shows mixed signal intensity. (B) T2-weighted image; the tumor shows mixed intensity. (C) Diffusion-weighted image; the tumor shows high intensity. (D) Apparent diffusion coefficient mapping; the tumor shows low intensity.

However, the AFB smear and culture from the prostate biopsy and urine were negative. The patient remained under careful monitoring and without changes in his status until the scrotal swelling was noted. Figure 3 summarizes the patient's clinical course timeline, including clinical events, chemotherapy, diabetes medications, and $\mathrm{HbAlc}$ level.

Physical examination revealed the following: body mass index, 32.9 (height $170 \mathrm{~cm}$, weight $95 \mathrm{~kg}$ ); body temperature, $37.5^{\circ} \mathrm{C}$; and blood pressure, $119 / 79 \mathrm{mmHg}$ with a regular pulse at 107 beats $/ \mathrm{min}$. His scrotum was bilaterally enlarged with mild tenderness and pus discharge from a scrotal fistula. Scrotal ultrasonography revealed diffusely enlarged bilateral epididymis with a heterogeneous and hypoechogenic texture (Figure 4A and B). On magnetic resonance imaging, the mass lesion showed slightly higher and lower signal intensities relative to testicular parenchyma on T1-weighted and T2-weighted images, respectively
(Figure 4C and D). The results of blood and urine examination are shown in Table 1. The glycated hemoglobin was $7.5 \%$, which suggested that the DM was poorly controlled and complicated by stage 2 nephropathy. The estimated glomerular filtration rate was decreased relative to a baseline value of approximately $50 \mathrm{~mL} / \mathrm{min} / 1.73 \mathrm{~m}^{2}$. There was a mild elevation of C-reactive protein, but neither pyuria nor hematuria was observed. The urine was sterile. The AFB smear, AFB culture, and Mtb PCR of the urine and pus discharge from the scrotal fistula were negative. Bilateral epididymectomy was then performed, and pathological examination demonstrated epithelioid cell granuloma with Langhans giant cell and caseous necrosis. Although the AFB smear was negative, the tissue tested positive for $M t b$ PCR. AFB culture test confirmed $M t b$, and the isolated strain was resistant to INF, RIF, and EB. Table 2 summarizes the results of TB investigation. Finally, 


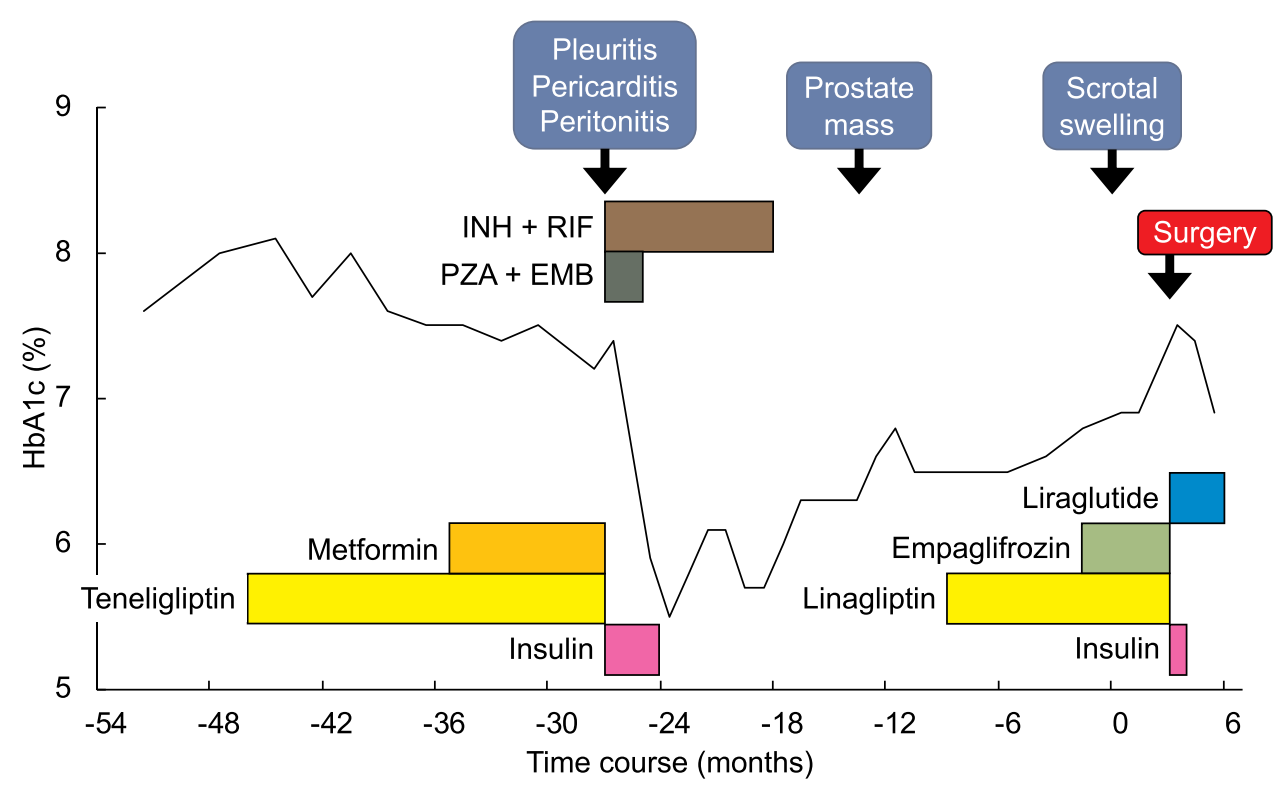

Figure 3 Timeline of the patient's clinical course. The horizontal axis indicates the timeline. The vertical axis indicates the HbAIc level. The black line indicates changes in $\mathrm{HbAlc}$. Horizontal bars indicate medications for tuberculosis and diabetes mellitus.

Abbreviations: EMB, ethambutol; HbAlc, glycated hemoglobin; INH, isoniazid; PZA, pyrazinamide; RIF, rifampin.
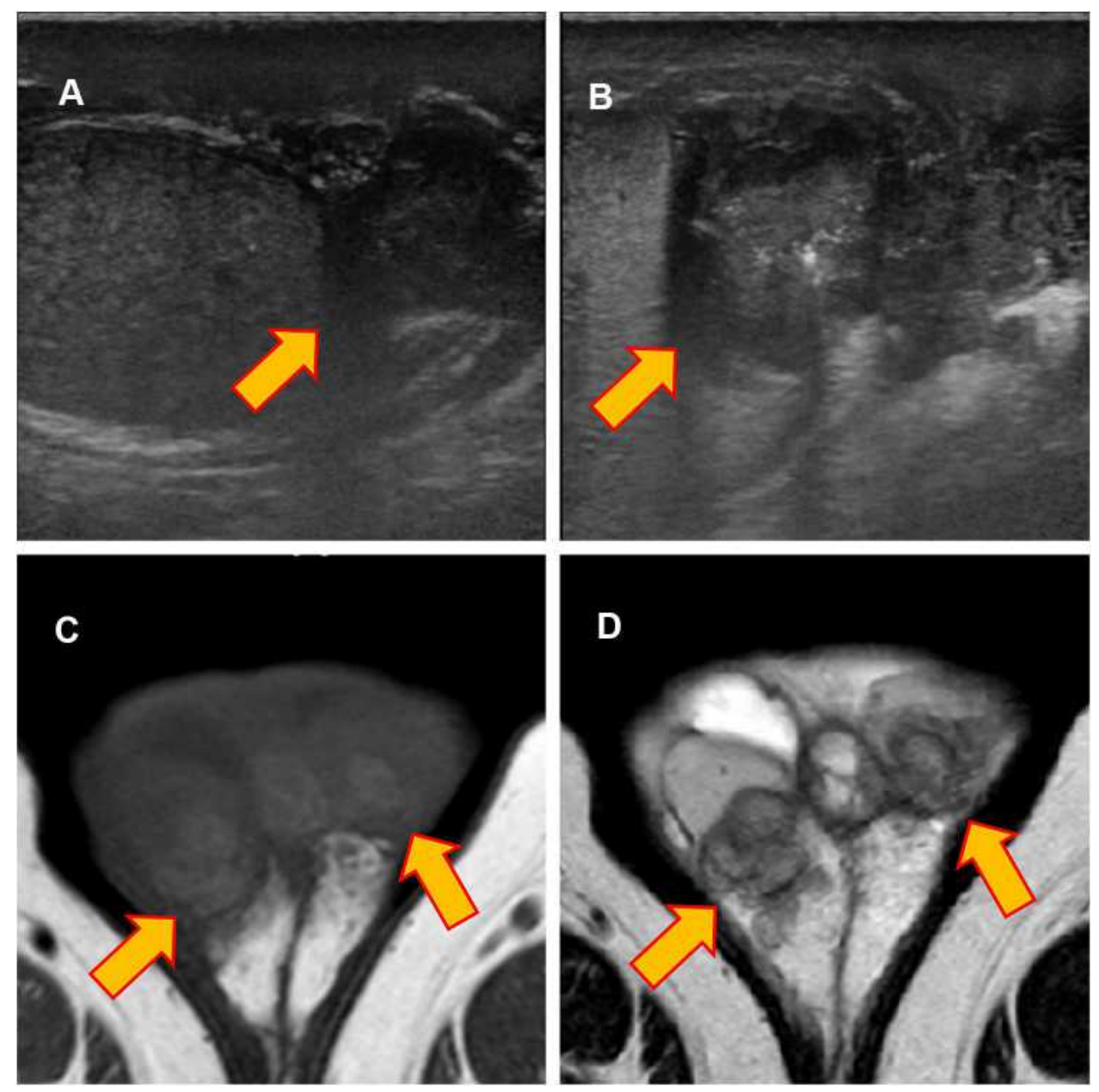

Figure 4 Imaging findings of the scrotum. Scrotum ultrasonography and horizontal plane on magnetic resonance imaging are shown. The yellow arrow indicates the tumor. (A and B) Right and left scrotum ultrasonography. Bilaterally enlarged epididymis demonstrating heterogeneous and hypoechogenic texture. (C) TI-weighted image; the tumor shows slightly higher intensity relative to testicular parenchyma. (D) T2-weighted image; the tumor shows lower intensity relative to testicular parenchyma. 
Table I Blood and Urine Examinations

\begin{tabular}{|c|c|c|c|}
\hline & Values & Units & References \\
\hline White blood cell & 8000 & $/ \mu \mathrm{L}$ & $(3300-8600)$ \\
\hline Hemoglobin & 13.0 & $\mathrm{~g} / \mathrm{dL}$ & $(13.7-16.8)$ \\
\hline Platelet & 235 & $10^{3} / \mu \mathrm{L}$ & $(158-348)$ \\
\hline Total bilirubin & 0.40 & $\mathrm{mg} / \mathrm{dL}$ & $(0.4-1.5)$ \\
\hline Aspartate aminotransferase & 22 & $U / L$ & $(13-30)$ \\
\hline Alanine aminotransferase & 21 & $U / L$ & $(10-42)$ \\
\hline Alkaline phosphatase & 332 & $U / L$ & $(106-322)$ \\
\hline Gamma glutamyl transpeptidase & 108 & $\mathrm{U} / \mathrm{L}$ & $(13-64)$ \\
\hline Blood urea nitrogen & 24.7 & $\mathrm{mg} / \mathrm{dL}$ & $(8.0-20.0)$ \\
\hline Creatinine & 1.57 & $\mathrm{mg} / \mathrm{dL}$ & $(0.65-1.07)$ \\
\hline eGFR & 36.4 & $\mathrm{~mL} / \mathrm{min} / \mathrm{I} .73 \mathrm{~m}^{2}$ & \\
\hline Uric acid & 6.5 & $\mathrm{mg} / \mathrm{dL}$ & $(3.7-7.0)$ \\
\hline Sodium & 140 & $\mathrm{mEq} / \mathrm{L}$ & $(|38-| 45)$ \\
\hline Potassium & 4.6 & $\mathrm{mEq} / \mathrm{L}$ & $(3.6-4.8)$ \\
\hline Chloride & 104 & $\mathrm{mEq} / \mathrm{L}$ & $(10 \mathrm{I}-108)$ \\
\hline C-reactive protein & 2.51 & $\mathrm{mg} / \mathrm{dL}$ & $(\leq 0.2)$ \\
\hline Albumin & 4.0 & $\mathrm{~g} / \mathrm{dL}$ & $(4.1-5.1)$ \\
\hline Plasma glucose & 139 & $\mathrm{mg} / \mathrm{dL}$ & $(73-109)$ \\
\hline $\mathrm{HbAlc}$ & 7.5 & $\%$ & $(4.6-6.2)$ \\
\hline Anti-HIV-I/2 antibodies & - & & \\
\hline Urine $\mathrm{pH}$ & 5.5 & & $(5-7)$ \\
\hline Urine specific gravity & 1.019 & & $(1.005-1.020)$ \\
\hline Urine protein & \pm & & \\
\hline Urine glucose & $4+$ & & \\
\hline Urine occult blood & - & & \\
\hline Urine white blood cell & - & & \\
\hline Urine ACR & 98.7 & $\mathrm{mg} / \mathrm{gcre}$ & $(1.9-13.3)$ \\
\hline
\end{tabular}

Notes: Reference ranges are shown in parentheses in the far right column. eGFR was calculated as follows: $194 \times$ Creatinine $[\text { mg } / \text { dL }]^{-1.094} \times$ Age $[\text { years }]^{-0.287}$. Abbreviations: ACR, albumin to creatinine ratio; eGFR, estimated glomerular filtration rate; HbAlc, glycated hemoglobin; HIV, human immunodeficiency virus.

Table 2 Summary of Evaluations for Tuberculosis in Affected Organs

\begin{tabular}{|l|c|c|c|}
\hline & Pleura & Prostate & Epididymis \\
\hline Time of evaluation & Before chemotherapy & 4 months after chemotherapy & 2 months after chemotherapy \\
Histopathology & $\begin{array}{c}\text { Epithelioid cell granuloma, Langhans } \\
\text { giant cell, caseous necrosis }\end{array}$ & $\begin{array}{c}\text { Epithelioid cell granuloma, Langhans } \\
\text { giant cell, caseous necrosis }\end{array}$ & $\begin{array}{c}\text { Epithelioid cell granuloma, Langhans } \\
\text { giant cell, caseous necrosis }\end{array}$ \\
AFB smear & Negative & Negative & Negative \\
AFB culture & Negative & Negative & Positive \\
Mtb PCR & Negative & Negative & Positive \\
Drug sensitivity test & Unavailable & Unavailable & INF, RIF, and EMB resistance \\
\hline
\end{tabular}

Abbreviations: AFB, acid-fast bacilli; EMB, ethambutol; INH, isoniazid; Mtb, Mycobacterium tuberculosis; PCR, polymerase chain reaction; RIF, rifampin.

a diagnosis of multi-drug resistant (MDR) TB epididymitis was made. The patient was transferred to the TB specialized hospital for further evaluation and treatment, and then chemotherapy comprising levofloxacin, ethionamide, cycloserine, para-aminosalicylic acid, and pyrazinamide was initiated.

\section{Discussion}

Pulmonary disease is the most common form of TB, but TB can affect any organ of the body. Extrapulmonary TB refers to the involvement of organs outside the pulmonary parenchyma. Similar to pulmonary TB, chemotherapy is the mainstay of treatment of extrapulmonary TB. Two months of 
intensive phase therapy using INH, RIF, PZA, and EMB, followed by 4 months of continuous phase therapy using INH and RIF, are justified for pleural, pericardial, peritoneal, and urogenital TB. ${ }^{4}$ Meanwhile, urogenital TB is often diagnosed late because of its non-specific clinical manifestation and lack of specific diagnostic tests. Therefore, over half of patients with urogenital TB require surgery, as evidenced in a previous review. ${ }^{6}$ The success of chemotherapy depends on multiple factors, including host and bacilli characteristics. Extensive disease at baseline, poor treatment adherence, drug resistance, malnutrition, malabsorption, and DM have been associated with poor treatment response. ${ }^{4}$ Considering the disease extensiveness and co-existing DM in this patient, the chemotherapy was extended to nine months. Chemotherapy led to markedly improved pleural, pericardial, and peritoneal symptoms. However, MDR-TB epididymitis occurred 18 months after completing the chemotherapy.

Extrapulmonary TB has been reported in $5-45 \%$ of TB patients, and the proportion of urogenital $\mathrm{TB}$ comprises $2-20 \%$ of extrapulmonary TB cases. ${ }^{7}$ TB infections can affect the entire male urogenital and reproductive systems. The epididymis can be seeded with $M t b$ by hematogenous spread, retrograde spread from the prostate, or direct spread from the lower urinary tract. ${ }^{7}$ The frequency of epididymitis is reportedly $11.8-55.5 \%$ in male urogenital TB patients. ${ }^{8}$ The latent period between primary infection and urogenital TB development is typically 20 years or more. ${ }^{9}$ Considering the long latent period of epididymitis, TB relapse was more likely than re-infection in this present case.

MDR-TB refers to a TB strain, resistant to two or more anti-TB drugs, including INH and RIF. Antibiotic susceptibility testing before the initial chemotherapy was unavailable in this present case. However, multi-drug resistance most likely developed during treatment because there was an initial improvement of the pleural, pericardial, and peritoneal involvements. Eradication of $M t b$ is crucial in TB management because insufficient treatment can lead to disease relapse and drug resistance development. Inadequate treatment and poor adherence are risk factors associated with MDR-TB development. ${ }^{10}$ Similarly, DM was reported to be associated with MDR-TB and poor treatment outcomes. A previous meta-analysis of observational studies showed that TB patients with DM had a twofold higher risk of MDR-TB (Odds ratio, 1.97; 95\% confidence interval [CI], 1.58-2.45) than TB patients without DM. $^{11}$ Additionally, in another meta-analysis of observational studies, comorbid DM in TB patients was associated with increased risk of treatment failure and death (Relative risk [RR], 1.69; 95\% CI, 1.36-2.12), death (RR, 1.89; 95\% CI, 1.52-2.36), and disease relapse (RR, 3.89; 95\% CI, 2.43-6.23). ${ }^{12}$ DM negatively affects TB treatment via impaired immunity and altered anti-TB drugs' pharmacokinetics. CD4-positive T cells are essential in protecting against TB. ${ }^{13}$ However, a recent in-vitro study found that TB patients with DM exhibited an altered CD4-positive T-cell mediated immunity to $M t b .{ }^{14}$ Additionally, previous pharmacokinetic studies reported decreased bioavailability of major anti-TB drugs, such as rifampin, isoniazid, pyrazinamide, and ethambutol, in TB patients with DM. ${ }^{15-21}$ Given these circumstances, the coexistence of poorly controlled DM may involve an unfavorable clinical course in this case.

The differential diagnosis of scrotal mass includes epididymitis, testicular cancer, testicular torsion, testicular appendage torsion, inguinal hernia, hematocele, hydrocele, and varicocele. ${ }^{22}$ Epididymitis is often caused by Chlamydia trachomatis and Neisseria gonorrhoeae and gives rise to scrotal swelling, scrotal erythema, fever, and dysuria. ${ }^{22}$ Meanwhile, $M t b$ is a possible bacterial etiology for epididymitis, as described in this present case. Identification of $M t b$ in clinical samples is the gold standard for diagnosing TB. However, Mtb detection is sometimes challenging in patients with scrotal TB (TB of the epididymis, testis, or vas deferens). Bacteriological assessment based on AFB smear and AFB culture using the urine sample is often performed because these are easily accessible and non-invasive. However, the diagnostic sensitivities of AFB smear and AFB culture test are reportedly $42.1-52.1 \%$ and $10.7-90.0 \%$, respectively. ${ }^{8}$ Thus, a negative result does not rule out TB. Biopsy and fine-needle aspiration cytology are alternative procedures to detect $M t b$. However, these are avoided if malignancy is considered because of the risk of tumor cell seeding in the needle tract. ${ }^{7}$ Hence, scrotal TB is often diagnosed late. The mean interval from the emergence of clinical symptoms to scrotal TB diagnosis is reported to be 142 days. ${ }^{23}$ Additionally, $21.4 \%$ of patients with scrotal TB are diagnosed only after surgical intervention. ${ }^{24}$ A combination of clinical, bacteriological, histopathological, and radiographical assessment is required for an accurate diagnosis. TB should be included in the differential diagnosis of scrotal mass among patients with a history of TB. 


\section{Conclusion}

This present case suggested that the optimal treatment regimen and duration for extrapulmonary TB with unknown drug susceptibility remain debatable. The ninemonth regimen was insufficient in some cases. Close follow-up is essential, and scrotal mass in patients with a history of TB must prompt consideration for $\mathrm{TB}$ involvement.

\section{Abbreviations}

AFB, acid-fast bacilli; DM, diabetes mellitus; EMB, ethambutol; HbAlc, glycated hemoglobin; INH, isoniazid; MDR, multi-drug resistant; Mtb, Mycobacterium tuberculosis; PCR, polymerase chain reaction; PZA, pyrazinamide; RIF, rifampin; TB, tuberculosis.

\section{Ethics Approval and Informed Consent}

The patient described in this study provided permission to publish data and accompanying images, and written informed consent was obtained. A formal ethical review by an institutional review board was not required because this is a case report.

\section{Acknowledgments}

This report was not funded by any specific grant from funding agencies in the public, commercial, or not-forprofit sectors.

\section{Disclosure}

The authors report no conflicts of interest in this work.

\section{References}

1. Kyu HH, Maddison ER, Henry NJ. The global burden of tuberculosis: results from the Global Burden of Disease Study 2015. Lancet Infect Dis. 2018;18(3):261-284. doi:10.1016/S1473-3099(17)30703-X

2. Narasimhan P, Wood J, Macintyre CR, Mathai D. Risk factors for tuberculosis. Pulm Med. 2013;2013:828939. doi:10.1155/2013/828939

3. Jeon CY, Murray MB. Diabetes mellitus increases the risk of active tuberculosis: a systematic review of 13 observational studies. PLoS Med. 2008;5(7):e152. doi:10.1371/journal.pmed.0050152

4. Nahid P, Dorman SE, Alipanah N, et al. Official American Thoracic Society/Centers for Disease Control and Prevention/Infectious Diseases Society of America Clinical Practice Guidelines: treatment of drug-susceptible tuberculosis. Clin Infect Dis. 2016;63(7):e147e195.

5. Wang JY, Lee MC, Shu CC, et al. Optimal duration of anti-TB treatment in patients with diabetes: nine or six months? Chest. 2015;147(2):520-528. doi:10.1378/chest.14-0918

6. Figueiredo AA, Lucon AM. Urogenital tuberculosis: update and review of 8961 cases from the world literature.. Rev Urol. 2008;10 (3):207-217.
7. Muneer A, Macrae B, Krishnamoorthy S, Zumla A. Urogenital tuberculosis - epidemiology, pathogenesis and clinical features. Nat Rev Urol. 2019;16(10):573-598.

8. Figueiredo AA, Lucon AM, Srougi M. Urogenital tuberculosis. Microbiol Spectr. 2017;5:1. doi:10.1128/microbiolspec.TNMI70015-2016

9. Christensen WI. Genitourinary tuberculosis: review of 102 cases. Medicine (Baltimore). 1974;53(5):377-390. doi:10.1097/00005792197409000-00004

10. Jain A, Dixit P. Multidrug-resistant to extensively drug resistant tuberculosis: what is next? $J$ Biosci. 2008;33(4):605-616. doi:10.1007/s12038-008-0078-8

11. Tegegne BS, Mengesha MM, Teferra AA, Awoke MA, Habtewold TD. Association between diabetes mellitus and multi-drug-resistant tuberculosis: evidence from a systematic review and meta-analysis. Syst Rev. 2018;7(1):161. doi:10.1186/s13643-0180828-0

12. Baker MA, Harries AD, Jeon CY, et al. The impact of diabetes on tuberculosis treatment outcomes: a systematic review. BMC Med. 2011;9:81. doi:10.1186/1741-7015-9-81

13. Cooper AM. Cell-mediated immune responses in tuberculosis. Аnпи Rev Immunol. 2009;27:393-422. doi:10.1146/annurev. immunol.021908.132703

14. Kumar NP, Moideen K, George PJ, Dolla C, Kumaran P, Babu S Coincident diabetes mellitus modulates Th1-, Th2-, and Th17-cell responses in latent tuberculosis in an IL-10- and TGF- $\beta$-dependent manner. Eur $J$ Immunol. 2016;46(2):390-399. doi:10.1002/ eji.201545973

15. Nijland HM, Ruslami R, Stalenhoef JE, et al. Exposure to rifampicin is strongly reduced in patients with tuberculosis and type 2 diabetes. Clin Infect Dis. 2006;43(7):848-854. doi:10.1086/507543

16. Babalik A, Ulus IH, Bakirci N, et al. Plasma concentrations of isoniazid and rifampin are decreased in adult pulmonary tuberculosis patients with diabetes mellitus. Antimicrob Agents Chemother. 2013;57(11):5740-5742. doi:10.1128/AAC.01345-13

17. Chang MJ, Chae JW, Yun HY, et al. Effects of type 2 diabetes mellitus on the population pharmacokinetics of rifampin in tuberculosis patients. Tuberculosis (Edinb). 2015;95(1):54-59. doi:10.1016/j. tube.2014.10.013

18. Medellín-Garibay SE, Cortez-Espinosa N, Milán-Segovia RC, et al. Clinical pharmacokinetics of rifampin in patients with tuberculosis and type 2 diabetes mellitus: association with biochemical and immunological parameters. Antimicrob Agents Chemother. 2015;59 (12):7707-7714. doi:10.1128/AAC.01067-15

19. Kumar AK, Chandrasekaran V, Kannan T, et al. Anti-tuberculosis drug concentrations in tuberculosis patients with and without diabetes mellitus. Eur J Clin Pharmacol. 2017;73(1):65-70. doi:10.1007/ s00228-016-2132-z

20. Alfarisi O, Mave V, Gaikwad S, et al. Effect of diabetes mellitus on the pharmacokinetics and pharmacodynamics of tuberculosis treatment. Antimicrob Agents Chemother. 2018;62(11). doi:10.1128/ AAC.01383-18.

21. Mtabho CM, Semvua HH, van den Boogaard J, et al. Effect of diabetes mellitus on TB drug concentrations in Tanzanian patients. J Antimicrob Chemother. 2019;74(12):3537-3545. doi:10.1093/jac/ dkz368

22. Crawford P, Crop JA. Evaluation of scrotal masses. Am Fam Physician. 2014;89(9):723-727.

23. Lee IK, Yang WC, Liu JW. Scrotal tuberculosis in adult patients: a 10-year clinical experience. Am J Trop Med Hyg. 2007;77 (4):714-718. doi:10.4269/ajtmh.2007.77.714

24. Kulchavenya E, Khomyakov V. Male genital tuberculosis in Siberians. World J Urol. 2006;24(1):74-78. doi:10.1007/s00345005-0048-9 


\section{Publish your work in this journal}

Therapeutics and Clinical Risk Management is an international, peerreviewed journal of clinical therapeutics and risk management, focusing on concise rapid reporting of clinical studies in all therapeutic areas, outcomes, safety, and programs for the effective, safe, and sustained use of medicines. This journal is indexed on PubMed Central, CAS,
EMBase, Scopus and the Elsevier Bibliographic databases. The manuscript management system is completely online and includes a very quick and fair peer-review system, which is all easy to use. Visit http://www.dovepress.com/testimonials.php to read real quotes from published authors.

Submit your manuscript here: https://www.dovepress.com/therapeutics-and-clinical-risk-management-journal 